International Journal of Linguistics, Literature and Culture
Available online at https://sloap.org/journals/index.php/ijllc/
Vol. 4, No. 4, July 2018, pages: $86 \sim 102$
ISSN: $2455-8028$
https://sloap.org/journals/index.php/ijllc/article/view/270

Salient Socio-stylistic Traits of English and Arabic Junior Songs

Zahra Lutfi Hussein

\section{Article history:}

Received: 15 February 2018

Revised: 26 June 2018

Approved: 19 July 2018

Published: 27 July 2018

\section{Keywords:}

Junior Songs;

Lexical Level;

Socio-stylistics;

Syntactic Level;

Figurative Devices;

Belonging and Othering;

\begin{abstract}
Children songs exhibit various socio-stylistic features by which song authors manufacture special constructions to enroll the new consumers within grownups world. Practically, song authors exert their effort to be very close to juniors' minds, through the mediation of fun, imagination, education, and moral conventions. They utilize children register in transferring their messages, and functionalize different linguistic levels to achieve their aims. Thus, this paper aims to examine the socio-stylistic traits of 100 junior songs in both English and Arabic languages. Making use of Fergunson (1996) approach concerning the factors affecting children communication system (register predominance), interacting with two stylistic models; Leech and Short modal's 2007 of lexical and figurative devices prospects; and Thornborrow and Wareing modals (1998) of syntactic prospects, the lexical, syntactic and figurative devices in the chosen data express different outstanding traits such as belonging, dynamism, decontextualization, dedication, and imagination. The study concludes that socio-stylistic prospects applied to both languages result in converting an introduction to the new world conventions and unconsciously grafting childhood with friendly othering world. Junior songs can be considered the first invitation was given to children in their early phase to interact grownups worlds, besides their delightful, fun and deduction effects.
\end{abstract}

2455-8028 ${ }^{\circledR}$ Copyright 2018. The Author. This is an open-access article under the CC BY-SA license (https://creativecommons.org/licenses/by-sa/4.0/) All rights reserved.

\title{
Author correspondence:
}

Zahraa Ali Dawood,

MA candidate, Linguistics Program Studies,

Mustansiriyah University, Baghdad, Iraq,

Email address: zahali2016@gmail.com

\footnotetext{
${ }^{a}$ Department of English Language and Literature, College of Arts, Mustansiriyah University, Baghdad, Iraq

${ }^{b}$ Department of English Language and Literature, College of Arts, Mustansiriyah University, Baghdad, Iraq
} 


\section{Introduction}

Basically, little children between (3-6) years old go to specific places and kindergartens to acquire fun, morals, and education. Nearly, all parents are inclined to make their own children, firstly socially involved, then well educated. Significantly, junior songs are one of the most pivotal methods to facilitate this involvement. Junior songs are created and employed linguistically for the benefits of numerous child necessities, and social enrollment is one of its main consequences.

The delightful prosodic connotation of these literary texts urges juniors to memorize, repeat, and chant these songs together again and again. Sensibly, these anthems indirectly cultivate them socially, educationally and delightfully. Respectively, to be nearer to juniors' minds, song authors disguise under the cloak of children register and compensate between grownups world and childhood. To manufacture child socially, Ferguson (1996:98) asserts that "in adjusting our speech for talking to children... we are essentially exercising deep-seated biological capabilities even more universal than we thought". Also, he focuses on both target register and on language varieties, and which form and function they convey. Actually, junior songs are synthesized of both special sociological features, aggregate with the stylistic, lexical, syntactic and figurative devices.

As one of children literature domain, children songs, which also called "Anasheed" in Arabic, constitute a prosodic simple composition characterized by its simple constructions and its simple vocabulary, rhymed eloquently to be chanted in a group or individually. In other words, it is a human performance of music work that aggregates literary text with a tune (العناني,2013:155). Put it another way, a child song is" a multimodal super-genre that mediates between words and music" Fornäs (2003:1).

To sum up, junior songs implement magnificent social and linguistic effects that facilitate child steps towards the grownup world.

\section{Songs in General}

Ferguson (1996:97) proposes that each group of individuals is triggered to communicate by specific social context, depending on the situation, participants, and message paradigm. Foremost, individuals tend to develop special linguistic markers and aggregate communication setting with the register in each variety. This notion entirely is applied to children genre.

Thus deliberately, junior song authors intended to include rhythms, simplicity, imagination, belonging, deduction, dynamism, movement, repetition, and pleasure, exploiting linguistic levels to fulfill social, educational and delightful prospects.

Concerning children literature, mainly both English and Arabic languages witness the same conducting traits of songs, which are ascribed by the amalgamation of education with fun. Yet, factors such as language type, culture, and social differences deviate the destination of the contrastive process.

\section{Stylistics}

Many numerous attempts have been accomplished by several scholars to cycle stylistics concept, yet each one of them has a special point of view, innovated one or accumulated on previous one since different approaches correlate with different linguistic branches. Verdonk (2002:3) defines stylistics as a "distinctive linguistic expression" Leech (2008:3-6) practically asserts the main sphere of stylistics as the scope between the intended meaning and linguistic description, attributing the scene to two conducting traits "Chain and Choices"(Leech:18).

(1986:94-99) notes the difficulty posited in picking out certain linguistic choices to be parallel to consumers, besides the concordances or contradiction generated from debating between artistic roles and aims of writing. e.g. instead of committing to complete sentences, using phrases in this educational genre to express economic, contextual and persuasion prospects, and tempt children to listen, imagine, coordinate, and repeat. Additionally, (الهيتي) clarifies children aversion or lack of response against molded templates and regular norms which tune with Redford (2004:13) who previews children stubbornness with deducted style and direct order, So, the ritual style followed with children songs should be amalgamated with fun and delight to persuade them to perceive and comprehend.

Leech (2008:198-199) asserts the necessity of mutual assumption between addressee and addresser, which will result in stability of communication and common ground comprehension. Briefly, he expounds a vital basis of educational stylistics that fills the communication gap between a producer and a consumer and focuses on three

Lutfi Hussein, A., \& Ali Dawood, Z. (2018). Salient socio-stylistic traits of English and Arabic junior songs. International Journal of Linguistics, Literature and Culture, 4(4), 86-102. 
triangle evidence the text, the speaker context, and the background of the text. And this will result in reviving more authentic genre and creating stability in the communication process.

\section{Socio Stylistics}

Wales (2014:400-401) proposes that stylistician main aim is to prevail, how the functional face of a text can be interpreted objectively and subjectively. Then, stylistics is extended to include the analysis of language varieties or registers. On his part, Leech (2008:54) affirms that stylistics is the "variation in language use that is predicted by the situational parameter".

Elaborately, Wales (2014:3) previews the sociolinguistic influence on stylistics and outlines Howard Giles accommodation theory which signifies that people commit changes in behaviors, and appropriately tending to be attuned to their partner, in other words depicting "Audience Design". Halliday (1978) identifies it as "the degree of emotive charge' between interlocutors or participants. He also proposes that social structure is limited and transmitted by language and vice versa. Fowler (1986) precludes that socio-cultural notions are stereotyped and indexed in any variety (Halliday:11).

Accumulatively, Charles Ferguson (1996:97) clarifies that each aggregated individuals communicate actively by special social prospects, based on interlocutors, situation, and message genre, elucidating the final semiotics outputs on language form, function and register.

So, junior song authors construct their texts based mainly on children register and codify their language with exceptional methods to implement their purposes.

\section{Socio-Stylistic Features}

'Socially desirable child' is the main target for mainly all parents, grafting their kids with society and shifting them to welcoming individuals inside grownups world is their ultimate aims for that phase. So, the primary socialization which children experience among others takes place in that early stage and developed critically in nursery places and kindergarten institutions, where there is a focus on many social prospects, disciplines, morals, gender differences, and asymmetrical relations (solidarity and power). Or else a child will be isolated from others and get delayed or anti-socialized the rest of his life.

Junior children need a specific practice to facilitate the process of fusion inside society and exploit their register to assist the desired effects, so a dedicated song at this stage is a perfect method. Focusing on Ferguson (1996:97-98) inquiries about register, communicative competence and its role in language developed especially for children, and how to dedicate children with their register shorten the way to reach the intended meaning or messages.

Morals, education, and fun are amalgamated in junior songs, and their authors utilize numerous linguistic tools to represent a mimicry to:

a) Imagination

Using many figurative devices (personification, metaphor, simile) and abstract nouns enhance the imaginative prospects in this genre.

b) Educational scopes and logic scaling

Functionalizing the declarative, imperative sentences, models, some particles such as 'not-vocative oh', and concrete nouns besides many other linguistic tools

c) Self- representing, belonging and the othering

Traits which reflect the belonging mood in using some pronouns (I, We, Mine, You, Your,...etc.), attributive adjectives, 'the' definite article and simple adverbs which represent child spatial awareness.

On the other hand, predictive adjectives, pronouns of the third person (he, she, it, they, them, him, her, themselves, etc) and the indefinite article " $a$, $a n^{\prime \prime}$ are produced in junior songs effectively. In general, these linguistic devices manufacture an othering mode and a foreignism sense, but in this genre, it is a friendly othering that persuades the little consumers to integrate socially (Hunt, 2004:105).

d) Simple and descriptive inspection

Junior songs efficiently portray the descriptive mode by the use of compound and complex sentences, conjunctions, concrete words, auxiliaries, etc (Russell,2005:2). 
e) De-contextual genre

This genre as an educational one is attributed to the rarity of context clues to be equivalent to both native and non-native consumers. Thus, adverbs, phrases, nonfinite verbs can utilize this credit, gaining more free space and liberty in chanting these poems everywhere (Hunt, 2004:523).

Thus, cultivating those consumers gradually by linguistic means grafting with children register to create a remarkable scheme and evoke them socially, educationally, and pleasurable.

\section{Research Methods}

The main procedures followed in this paper concerning the methodology section are of three parts, methods, data selection, and modal proposed for the analysis of the selected data.

\subsection{Method}

Examining the salient socio-stylistic traits of English and Arabic junior songs will be carried out via qualitative and quantitative methods. The quantitative part will base on the percentages of occurrences of lexical, syntactic, and figurative linguistic levels, whereas the qualitative ones on the subjective perspectives of these findings

\subsection{Sample (data)}

Concerning data selection, the researcher selected 100 junior songs, fifty ones for each language type, selected from Silberg, J. \& Schille, P.B. (2002) book "The Complete Book of Rhymes, Songs, Poems, Fingerplays, and Chants" and العيسى (2009) book "Swings chanted to children" for kindergarten juniors.

\subsection{Modal}

The modal posited in the analysis of the socio-stylistic traits is an eclectic one which is based on, Fergunson's (1996) view of children register from a sociological side, aggregating with both Leech and Short modal's (2007) for the lexical and figurative and Thornborrow and Wareing modal's (1998) for the syntactic level, from the stylistic side.

\subsection{Data Analysis}

To stimulate the eclectic modal proposed for both languages, the researcher's will paradigm linguistic tools under each level to cover the prospects mentioned in the socio-stylistic features for children genre depending on their register. Firstly, the lexical level is of two sections content words (nouns, verbs, adjectives, and adverbs) and function words (Particles, auxiliaries, modals, conjunctions, prepositions, pronouns, and articles) with many subsections under these items. Secondly, the syntactic level includes sentences types (interrogatives, declarative, imperatives, and exclamatory), sentence completeness (sentence and phrase), verb function (finite - nonfinite) and (passive-active). Thirdly, figurative devices involve personification, metaphor, and simile. All the aforementioned linguistic levels will be investigated from Fergunson's (1996) view about children register and language. Three examples for each language will be displayed to be examined in detailed.

Three English junior songs are selected to be analyzed in terms of lexical level, syntactic level, and figurative devices to shed lights on the most prominent socio-stylistic features cited

\section{- Five Little Pumpkins}

Five little pumpkins sitting on the gate

First one said "Oh my, It's getting late

Second one said "there're witches in the air

Third one said "We don't care"

Fourth one said "Let's run"

Fifth one said "Oh, it's just Halloween fun"

But whooo went the wind and out went the light

Lutfi Hussein, A., \& Ali Dawood, Z. (2018). Salient socio-stylistic traits of English and Arabic junior songs. International Journal of Linguistics, Literature and Culture, 4(4), 86-102. https://doi.org/10.21744/ijllc.v4n4.270 
And five little pumpkins rolled out of sight.

In this song, the author presents a comic scene of five pumpkins sitting on a gate and talking together about the "Halloween festival", which is a cultural event in western Christian society held on 31. October every year, and pumpkin is the main theme in that carnival. This song expresses many socio stylistic functions via linguistic levels as will be shown below. It mainly:

a) Dedicates juniors indirectly to count from one to five using (26 nouns, 13 verbs, 2 adjectives, 2 adverbs) and 7 declarative sentences and one particle (not),

b) Presents an imaginary portrayed by using personification six times and respire the pumpkins as a human talking and arguing beside (15) abstract nouns (light, sight, run, Halloween, etc.),

c) Expresses decontextualism by the rare use of adverbs (out) cited twice, and the "Five little pumpkins sitting on the gate " phrase which has no tense indication only a nonfinite verb (sitting),

d) States belonging and othering in different percentages, belonging postulated by the use of the following linguistic items, attributive adjectives (little) cited twice with their accompanied modifiers, the occurrence of (my, we, us) pronouns, and the definite (the) which are cited four times. This song contains (it) pronoun, cited twice, this rate functions slightly as an invitation to the consumer to see and integrate with the other in the new world,

e) The descriptive mode is clued by the use of (2) conjunctions, (5) complex and (2) compound sentences; these items provoke children's minds to search and linking things together logically. Simple mode is eloquently presented by the (7) declarative sentences, (2) simple sentences, (13) active verbs, and (11) concrete nouns, which all aggregate together presenting simplicity, directness, with logic form, and

f) The movement effect and activity mode are efficiently introduced via the dynamic and stative verbs, (12) dynamic verbs have been cited against (1) stative one.

- Miss Mary Mac

Miss Mary Mack, Mack, Mack,

All dressed in black, black, black,

With silver buttons, buttons, buttons,

All down her back, back, back.

She asked her mother, mother, mother,

For fifteen cents, cents, cents,

To see the elephant, elephant, elephant,

Jump over the fence, fence, fence.

He jumped so high, high, high,

He reached the sky, sky, sky,

And didn't come back, back, back,

Till the Fourth of July, ly, ly.

In this instance, the song author presents a girl whose name is Mary and he begins to describe her dressing and her movements and behaviors till the end of the song where the author recalls the commemorating of independence day in the United States (4th of July), which is a socio-cultural event in American society. However, this song records several socio- stylistic prospects as will be registered below. It essentially

a) Dedicates juniors indirectly in their behaviors with their mother, and how money (15 cents) can be used to buy fun and delight, the author functionalizes (26 nouns, 7 verbs, 13 adjectives, 1 adverb), 4 declarative sentences and one particle (not) to present deduction mode,

b) Presents the imaginary form synthesized by employing personification which respires the elephant as a male with "he' twice; and abstract nouns (Fourth, July); besides the comic tale of the flying elephant,

c) Expresses decontextualism by the rare use of adverbs, only one adverb (till), and the (7) phrases which have no tense indication and the (2) nonfinite verbs all these points present tense-free mode,

d) Belonging and othering exhibit in different percentages, belonging postulated feebly here, attributive adjectives cited only once (silver buttons), the definite (The) cited four times. The othering is noticed more with the pronouns (her, he) cited twice. This rate functions strongly as an invitation to the consumer to see and integrate with the other in the new world, portrayed by Miss Mary and the elephant, 
e) Postulates the descriptive mode clued by the use of (6) conjunctions, (5) complex and compound sentences; these occurrences provoke children's minds to search and link things together logically. The simple mode is presented eloquently by the (4) declarative sentences, (5) active verbs, and (24) concrete nouns which all aggregate together presenting simplicity, directness, and logic form, and

f) Invokes the movement effect and active mode, efficiently presented via the dynamic verbs; (6) dynamic verbs have been cited against (1) stative one.

\section{- Clouds}

What's fluffy white and float up high.

Like a pail of cotton in the sky?

And when the wind blows hard and strong

what very gently floats along?

What bring the rain?

What bring the snow?

That showers down on us below?

When you look up in the high blue sky

What is that thing you see float by?

(A cloud).

In this song, the author functionalizes the interrogative style to present a riddle. Significantly in using this style, the consumer sight is provoked and enhanced by different descriptive details to find the answer. In addition, sociostylistic prospects are embodied in this song as detailed through the following points:

a) Dedication and educational prospects in this song are directly postulated via the (5) interrogative sentences which are requests for an answer, so the author excludes other instruction devices such as declarative, imperative sentences and particles.

b) An imaginary prospect is portrayed by simile' Like a pail of cotton ', metaphor' fluffy white and float up high ', and personification" What brings the rain? What brings the snow?", and the abstract noun (pail). All these items integrate aggregately to motivate the juniors' minds to provoke their thinking and develop their perception.

c) Decontextualism is feeble in this song, three adverbs are cited 'Up, Along and Below', with one phrase' Like a pail of cotton in the sky ' and there is no non-finite verb against (9) finite verbs, thus the contextual prospect here is weak.

d) Belonging and othering are vitally presented in this genre, belonging postulated by the attributive adjective which is cited only once (fluffy white), pronouns registered three times (us, you, you), definite article (The) cited four times. The othering is recorded more with many devices such as the demonstrative pronouns (when, that, that), (7) predictive adjectives (high, hard, strong,...etc.), and (2) indefinite articles ' a -an'. Here, the otherness mode is elevated highly to encourage the consumers to search, think and interact with the grownup world.

e) The descriptive mode is signified by the used of (7) conjunctions and (5) complex and compound sentences, these items provoke children's minds to search and logically link things together. The simple mode is presented eloquently by (9) active verbs, and (8) concrete nouns which all aggregate together presenting simplicity, directness, and logic outline.

f) The movement effect and activity mode are efficiently presented via the (8) dynamic verbs against (2) stative one.

Tables $(1,2,3)$ below sum up all the percentages of occurrences concerning the English junior songs for the three proposed level, lexical, syntactic, and figurative devices.

Lutfi Hussein, A., \& Ali Dawood, Z. (2018). Salient socio-stylistic traits of English and Arabic junior songs. International Journal of Linguistics, Literature and Culture, 4(4), 86-102. https://doi.org/10.21744/ijllc.v4n4.270 
Table 1

Lexical level of English junior songs

\begin{tabular}{|c|c|c|c|c|c|c|c|c|c|}
\hline \multicolumn{10}{|c|}{ Lexical Level } \\
\hline \multirow{4}{*}{$\begin{array}{l}\text { Content } \\
\text { Words }\end{array}$} & \multirow{2}{*}{\multicolumn{2}{|c|}{ Nouns }} & \multirow{2}{*}{\multicolumn{2}{|c|}{792}} & \multirow[t]{2}{*}{$49 \%$} & \multicolumn{2}{|c|}{ Concrete } & 578 & $73 \%$ \\
\hline & & & & & & & & 214 & $27 \%$ \\
\hline & \multirow{2}{*}{\multicolumn{2}{|c|}{ Verbs }} & \multirow{2}{*}{\multicolumn{2}{|c|}{470}} & \multirow[t]{2}{*}{$29 \%$} & \multicolumn{2}{|c|}{ Stative } & 88 & $18.7 \%$ \\
\hline & & & & & & \multicolumn{2}{|c|}{ Dynamic } & 382 & $81.2 \%$ \\
\hline \multirow{7}{*}{$\begin{array}{c}1596 \\
55.8 \\
\%\end{array}$} & \multirow{2}{*}{\multicolumn{2}{|c|}{ Adj. }} & \multirow{2}{*}{\multicolumn{2}{|c|}{194}} & \multirow[t]{2}{*}{$12 \%$} & \multicolumn{2}{|c|}{ Attributive } & 126 & $65 \%$ \\
\hline & & & & & & \multicolumn{2}{|c|}{ Predictive } & 68 & $35 \%$ \\
\hline & \multirow{5}{*}{\multicolumn{2}{|c|}{ Adv. }} & \multirow{5}{*}{\multicolumn{2}{|c|}{140}} & \multirow[t]{5}{*}{$9.2 \%$} & \multicolumn{2}{|c|}{ Time } & 33 & $23.5 \%$ \\
\hline & & & & & & \multirow{2}{*}{\multicolumn{2}{|c|}{$\begin{array}{l}\text { Place } \\
\text { Manner }\end{array}$}} & 44 & $31.4 \%$ \\
\hline & & & & & & & & 44 & $31.4 \%$ \\
\hline & & & & & & \multicolumn{2}{|c|}{ Frequency } & 10 & $10 \%$ \\
\hline & & & & & & \multicolumn{2}{|c|}{ Degree } & 9 & $6.5 \%$ \\
\hline \multirow{2}{*}{$\begin{array}{l}\text { Function } \\
\text { Words }\end{array}$} & \multicolumn{2}{|c|}{ Pronouns } & \multicolumn{2}{|c|}{ Article } & \multirow[b]{2}{*}{$\begin{array}{l}\frac{n}{\pi} \\
\frac{\pi}{0} \\
\sum\end{array}$} & \multirow[b]{2}{*}{$\widehat{Z}$} & \multirow[b]{2}{*}{ 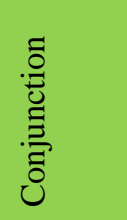 } & \multirow[b]{2}{*}{$\dot{2}$} & \multirow[b]{2}{*}{ D. } \\
\hline & $\mathrm{I}, \ldots$ & They,... & the & a-an & & & & & \\
\hline \multirow{3}{*}{$\begin{array}{c}1264 \\
44.19 \%\end{array}$} & 200 & 138 & 183 & 81 & 38 & 115 & 216 & 261 & 32 \\
\hline & $59.17 \%$ & $40.8 \%$ & $69.3 \%$ & $30.68 \%$ & \multirow[t]{2}{*}{$2.9 \%$} & \multirow[t]{2}{*}{$8.8 \%$} & \multirow[t]{2}{*}{$16.5 \%$} & $19.9 \%$ & $2.4 \%$ \\
\hline & & & & & & & & & \\
\hline
\end{tabular}

Table 2

Syntactic level of English junior songs'

\begin{tabular}{cccc}
\hline English Children Songs' & \multicolumn{2}{c}{ Syntactic Level } \\
\hline Sentences & Simple & 138 & $28 \%$ \\
and Phrases & Complex & 161 & $32 \%$ \\
& Phrase & 197 & $41 \%$ \\
Sentences Types & Total & 496 & $100 \%$ \\
& Interrogative & 27 & $9 \%$ \\
& Imperative & 64 & $20 \%$ \\
& Declarative & 220 & $69 \%$ \\
& Exclamatory & 6 & $2 \%$ \\
Finite and Non Finite Verbs & Total & 317 & $100 \%$ \\
& Finite & 409 & $83.46 \%$ \\
& Non- Finite & 81 & $16.5 \%$ \\
Active and Passive & Total & 409 & $100 \%$ \\
& Active & 405 & $99 \%$ \\
& Passive & 4 & $1 \%$ \\
\hline
\end{tabular}


Table 3

Figurative devices of English junior songs

\begin{tabular}{cccc}
\hline \multirow{2}{*}{ English Junior Songs' } & \multicolumn{3}{c}{ Figurative Devices } \\
& Simile & Metaphor & Personification \\
\hline Total 119 & 8 & 15 & 96 \\
Frequency rate $100 \%$ & $6.7 \%$ & $12.6 \%$ & $80.67 \%$ \\
\hline
\end{tabular}

\subsection{Arabic Data}

Fifty Arabic junior songs have been investigated in this study according to the aforementioned proposed modal. Three samples will be analyzed in detail in terms of socio-stylistic aspects.

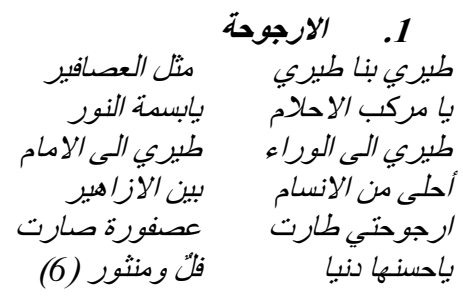

In this song the author describes a child talking to a swing, asking it to make him fly like birds, or as a fantasy boat, similar to the light of smile. The swing flies forward and backward prettier than the breeze between the flowers, turning to a bird with a charming look of spread jasmine. In this song different socio-stylistic prospects highlighted as will be shown below:

a) Instruction and direction prospects in this song are directly postulated via the (3) imperative sentences with the verb (طيري-fly) and the (3) presence of vocative (يا-yaa) as particle in the function words; particles such as / -yaa / and / Y - not/ present Instruction mode by vacating someone to direct or prohibit him/ her .

b) The imaginary prospect is portrayed by simile occurred once 'مثل العصافبر ', (4) metaphor cases in lines $(2,2,4,6)$, (5)personification in line $(1,1,3,3,5)$ with the verb (طيري) fly), and the (5) abstract nouns 'الاححلام,النور بسمة,الحسن,دنيا' . These items aggregate together to stimulate juniors' minds to imagine, think and expand their perception.

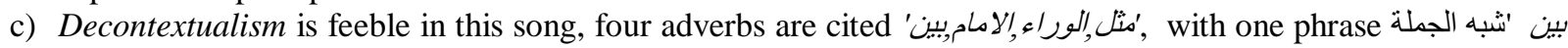
against (5) finite verbs, thus the decontextual prospect here is weak. Nonfinite verbs in Arabic are called "Masdar /لمصدر)" which is either an exaggerated form of adjective derivative from a verb such as (فعال، منثور,فتون , or a base verb preceded by' Result, Purpose, Exception, Preference' with specific particles such as (حتى, كي , مثل , كما , الا, سوى, فع الخ) (Drozdík, 2009:1).

d) Belonging and othering are stated vitally in this genre, belonging is postulated by the attributive adjectives

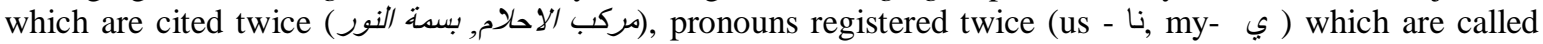

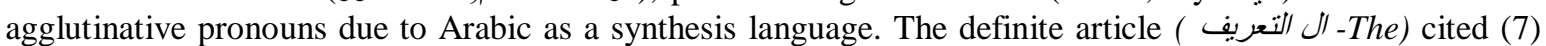
times. In the Othering side, pronouns of the third person cited three times "طارت, صسارت, حسنها (ه) the final (ta ت) and (هa ( ها - (2) agglutinative pronouns represent she in English, no predictive adjectives cited, and (2)

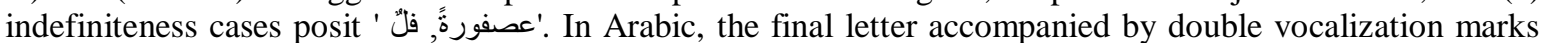
(تنوين فتح او ضم او كسر ) on the end of a word without "at the beginning can be counted as indefiniteness mark(الصرايرة, 2007:61). Here, the otherness mode is elevated highly to encourage the consumers to search, think and interact.

e) The simple mode is presented basically in this genre by (9) simple sentences,(5) active verbs, and (6) concrete nouns 'عصافير ,مركب,ارجوحة, ازاهير,انسام,فل', all these tools aggregate together presenting simplicity, directness, and logic. The descriptive mode is slightly presented by the use of (1) conjunction 'مثنل', (2) compound sentences, and one auxiliary 'صارت'. Stative verbs and predictive adjectives are missing, all the aforementioned tools give some stimulus effects to children's minds to search and link things together logically.

f) The movement effect and activity mode are efficiently presented via the (5) dynamic verbs examples with no stative one.

Lutfi Hussein, A., \& Ali Dawood, Z. (2018). Salient socio-stylistic traits of English and Arabic junior songs. International Journal of Linguistics, Literature and Culture, 4(4), 86-102. https://doi.org/10.21744/ijllc.v4n4.270 


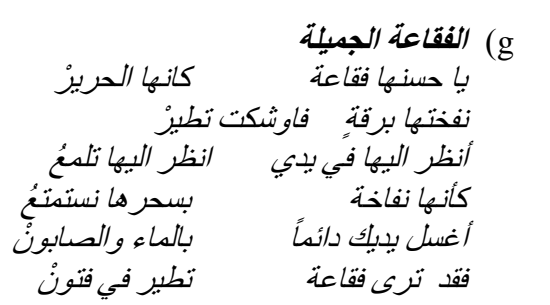

Indirectly, in this song, the author tempts little kids to take care of their cleanness and wash their hands carefully. He portrays a scene of a bubble flying, shining in an attractive glance, and instruct juniors to be keen on washing their hands with soap and water to see the charming bubble. The main socio stylistic aspects appear in the three levels of analysis are

a) Instruction and direction prospects in this song are indirectly conducted by the (3) imperative sentences with the verb (اغظل-look, اغظر- wash) and the once presence of vocative (يا-yaa) in line (1) as a particle in the function words.

b) The imaginary prospect is indexed by simile occurred twice " كأنها الحرير, and the (1) abstract noun "فتون"; these tools aggregate together to stimulate juniors' minds to imagine, think and perform these devices.

c) Decontextualism is slightly present in this song, three adverbs are cited (2) manner and (1) frequency adverb

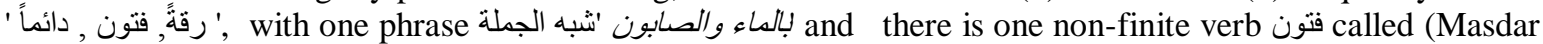
/المصدر) in Arabic against (5) finite verbs, thus the decontextual prospect here is weak.

d) Belonging and othering are shaped chiefly in this field, belonging is indexed by pronouns (نفختها, يدي) (3) - نائ (3),

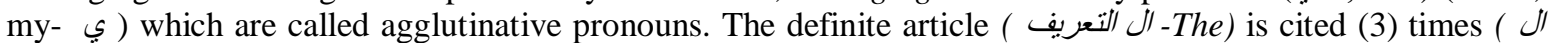

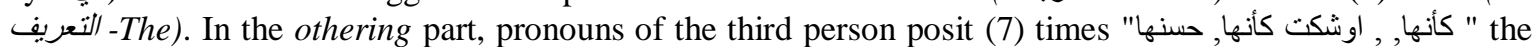
final (ta - ت) and (ha - ه) are agglutinative pronouns representing 'she' in English, no predictive adjective

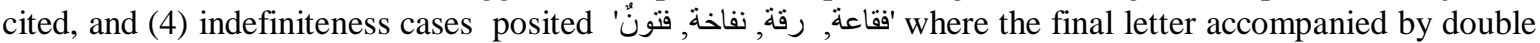
vocalization marks (تنوين فتح او ضم او كسر) to indicate the indefiniteness. Here, the otherness mode is elevated highly to encourage the consumers to search, think and interact.

e) The simple mode is basically presented in this genre by the (4) simple sentences, (9) active verbs, and (7) concrete nouns 'حرير, نفاخة, ماء, صابون, يديك, فقاعة, يدي,'. All these tools aggregate together presenting simplicity, directness, and logic. The descriptive mode is slightly presented by the use of (3) conjunctions 'متلكي', (5) compound sentences. Stative verbs and predictive adjectives are missing. All the aforementioned tools give some stimulus effects to children's minds to search and link things together logically.

f) The movement effect and activity mode are efficiently presented via (9) dynamic verbs against non-stative one.

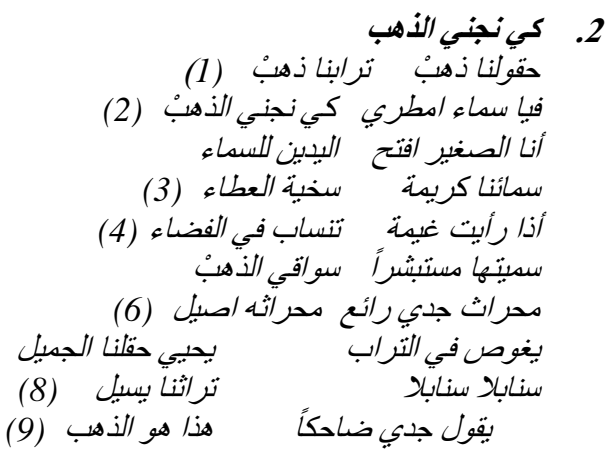

The author of this poem describes rain as the source of wealth and the fields and the soil are like gold. He portrays a scene of cultivating little children how rain is an important factor in agriculture process. The main socio stylistic aspects in the three levels of analysis are as follows:

a) Instruction and direction prospects in this song are indirectly conducted by one imperative sentences with the verb (مطري-rain) and the once presence of vocative (يا-yaa) in line (2) as a particle in the function word which indicates an order to the sky to rain. 
b) The imaginary prospect is conducted by metaphor occurred (5) times in line $(1,1,2,6,9)$, personification (4) times in line $(4,4,8,8)$ and (4) abstract noun "الصغير, عطاء, فضاء, تر اثناء". These tools aggregate together to inspire juniors' minds to imagine, feel and perform these devices.

c) Decontextualism is slightly presented in this song, no adverb and no phrase شبك الجملة posited only (2) nonfinite verb "ضاحكاً, مستبشر ا" against (9) finite verbs. Thus, the decontextual prospect here is weak.

d) Belonging and othering are basically formed in this field; belonging is indexed by (9) pronouns cited ( تقولنا (

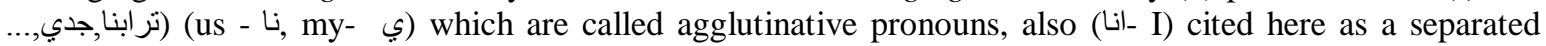
pronoun. Also, definite article ( ال التعريف-The) is recorded (9) times (التعريف-The). In the othering part, pronouns of the third person posit (3) times " محراثه, هذا, هو (6) _ (the final ha , indicating male reference).

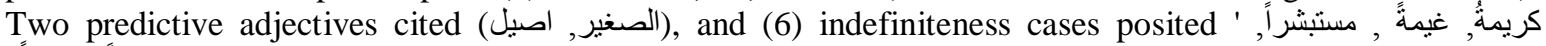

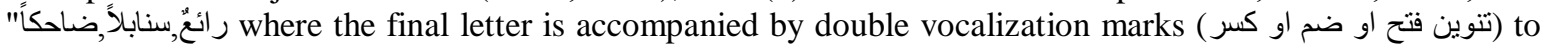
indicate the indefiniteness. Here, the otherness mode is elevated highly to encourage the consumers to search, think and interact.

e) The simple mode is basically presented in this genre by the (11) simple sentences, (9) active verbs, and (20) concrete nouns '.... سماء,محراث, جدي,ذهب,سنابلا. All these tools aggregate together presenting simplicity, directness, logic. The descriptive mode is slightly presented by the use of, (2) conjunctions 'أفري', (4) compound sentences. Stative verbs and predictive adjectives are missing. All the aforementioned tools give some stimulus outcomes to children's minds to search and link things together logically.

f) The movement effect and activity mode are efficiently presented via (8) dynamic verbs against (2) stative ones.

The three tables below summarize the whole occurrences and percentages of the components of the three linguistic levels proposed in this paper.

Table 4

Lexical level of Arabic junior songs

\begin{tabular}{|c|c|c|c|c|c|c|c|c|c|}
\hline \multirow{3}{*}{$\begin{array}{l}\text { Content } \\
\text { Words }\end{array}$} & \multicolumn{9}{|c|}{ Lexical Level } \\
\hline & \multirow{2}{*}{\multicolumn{2}{|c|}{ Nouns }} & \multirow{2}{*}{\multicolumn{2}{|c|}{1025}} & \multirow[t]{2}{*}{$56.84 \%$} & \multirow{2}{*}{\multicolumn{2}{|c|}{$\begin{array}{l}\text { Concrete } \\
\text { Abstract }\end{array}$}} & 510 & $49.8 \%$ \\
\hline & & & & & & & & 514 & $50.19 \%$ \\
\hline & \multirow{2}{*}{\multicolumn{2}{|c|}{ Verbs }} & \multirow{2}{*}{\multicolumn{2}{|c|}{466}} & \multirow[t]{2}{*}{$25.84 \%$} & \multicolumn{2}{|c|}{ Stative } & 124 & $26.6 \%$ \\
\hline & & & & & & \multicolumn{2}{|c|}{ Dynamic } & 342 & $73.3 \%$ \\
\hline 1803 & \multirow{2}{*}{\multicolumn{2}{|c|}{ Adj. }} & \multirow{2}{*}{\multicolumn{2}{|c|}{231}} & \multirow[t]{2}{*}{$12.81 \%$} & \multirow{2}{*}{\multicolumn{2}{|c|}{$\begin{array}{l}\text { Attributive } \\
\text { Predictive }\end{array}$}} & 141 & $61 \%$ \\
\hline $50.3 \%$ & & & & & & & & 90 & $39 \%$ \\
\hline & \multirow{5}{*}{\multicolumn{2}{|c|}{ Adv. }} & \multirow{6}{*}{\multicolumn{2}{|c|}{81}} & \multirow{5}{*}{$4.49 \%$} & \multirow{5}{*}{\multicolumn{2}{|c|}{$\begin{array}{c}\text { Time } \\
\text { Place } \\
\text { Manner } \\
\text { Frequency } \\
\text { Degree }\end{array}$}} & 25 & $30.9 \%$ \\
\hline & & & & & & & & 25 & $30.9 \%$ \\
\hline & & & & & & & & 17 & $21 \%$ \\
\hline & & & & & & & & 11 & $14 \%$ \\
\hline & & & & & & & & 3 & $3.7 \%$ \\
\hline \multirow{2}{*}{$\begin{array}{l}\text { Function } \\
\text { Words }\end{array}$} & \multicolumn{2}{|c|}{ Pronouns } & & & \multirow[b]{2}{*}{$\begin{array}{l}\frac{n}{\pi} \\
\frac{\pi}{0} \\
\Sigma\end{array}$} & \multirow{2}{*}{\multicolumn{2}{|c|}{ ẽ }} & \multirow[b]{2}{*}{ 这 } & \multirow[b]{2}{*}{ 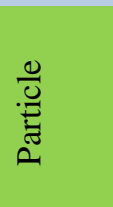 } \\
\hline & I & They & the & a-an & & & & & \\
\hline \multirow{3}{*}{$\begin{array}{l}1781 \\
49.6 \%\end{array}$} & 331 & 121 & 473 & 184 & 16 & 24 & 240 & 297 & 95 \\
\hline & $73.23 \%$ & $26.76 \%$ & $71.9 \%$ & $28.1 \%$ & $0.89 \%$ & $1.34 \%$ & $13.47 \%$ & $16.67 \%$ & $5.3 \%$ \\
\hline & \multicolumn{2}{|c|}{$25.37 \%$} & \multicolumn{2}{|c|}{$36.88 \%$} & & & & & \\
\hline
\end{tabular}

Lutfi Hussein, A., \& Ali Dawood, Z. (2018). Salient socio-stylistic traits of English and Arabic junior songs. International Journal of Linguistics, Literature and Culture, 4(4), 86-102. https://doi.org/10.21744/ijllc.v4n4.270 
Table 5

Syntactic level of Arabic junior songs

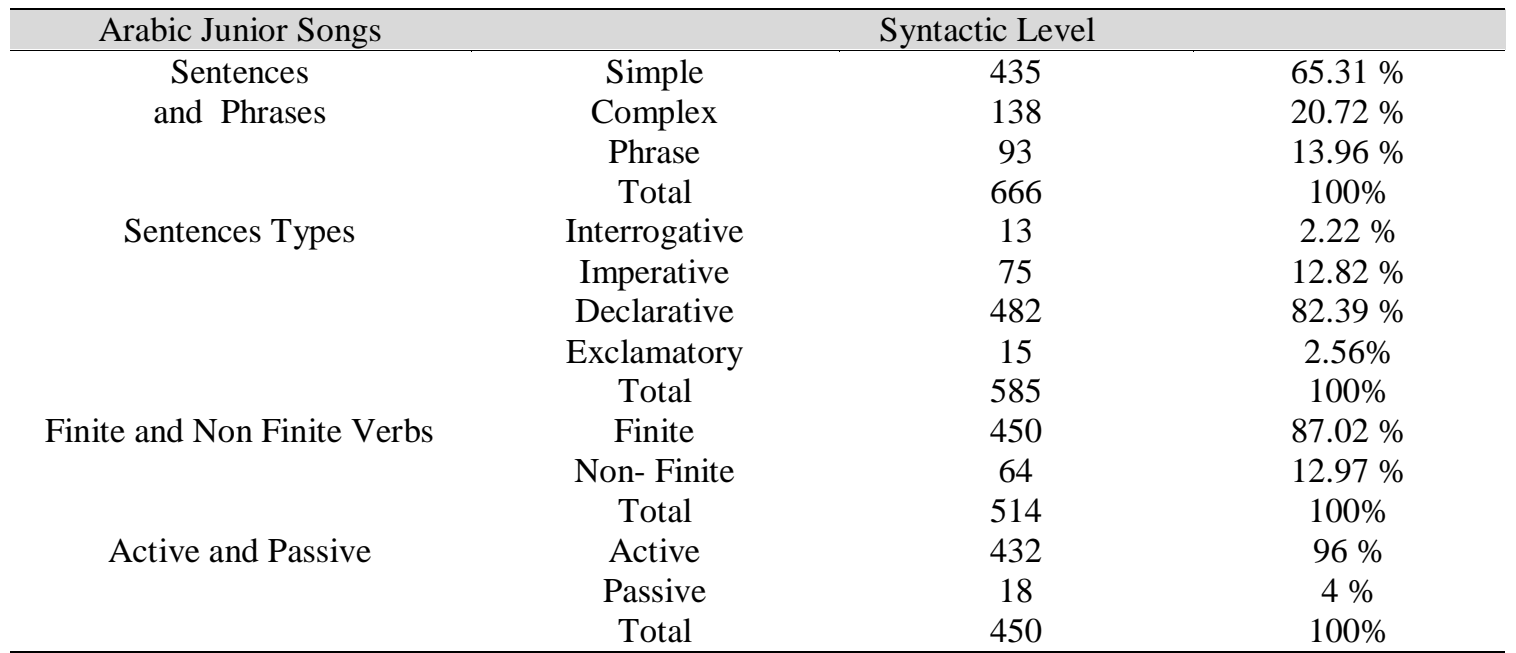

Table 6

The figurative devices of Arabic junior songs'

\begin{tabular}{cccc}
\hline \multirow{2}{*}{ Arabic Junior Songs' } & \multicolumn{3}{c}{ Figurative Devices } \\
& Simile & Metaphor & Personification \\
\hline Total 216 & 19 & 80 & 117 \\
Frequency rate $100 \%$ & $8.79 \%$ & $37.03 \%$ & $54.16 \%$ \\
\hline
\end{tabular}

\section{Results and Analysis}

The socio-stylistic analysis of Junior Songs in both languages has witnessed the following results which are presented below

a) The simple and descriptive mode fluctuate between the two languages, both groups utilize the same linguistic tools but with different percentages. English shows simplicity in using more concrete nouns and less passive voice, whereas Arabic indexes simplicity in using more simple, declarative sentences than in English besides the active mode has a parallel ratio to the English one which accumulates more simplicity than in English one. On the other hand, the descriptive mode was more prominent in the English part, in which English records high rates in using compound and complex sentences, conjunctions, and auxiliaries. Arabic exceeds English only by using more adjectives as indicating a descriptive model. The table below sums up these items.

Table 7

English and Arabic simple and descriptive mode

\begin{tabular}{cccc}
\hline Trait & Linguistic Tool & Time of Occurrences & Percentages \\
\hline Simple & Concrete Nouns & E. 578 & $73 \%$ \\
Mode & & A.510 & $49.8 \%$ \\
& Simple Sentences & E.138 & $28 \%$ \\
& & A.435 & $65.31 \%$ \\
& Declarative Sentences & E.220 & $69 \%$ \\
& & A.482 & $82.39 \%$ \\
Descriptive & Active Voice & E.405 & $99 \%$ \\
& & A.432 & $96 \%$ \\
& Compound \& Complex & E. 161 & $32 \%$ \\
\hline
\end{tabular}




\begin{tabular}{cccc}
\hline Trait & Linguistic Tool & Time of Occurrences & Percentages \\
\hline Mode & Sentences & A.138 & $20.72 \%$ \\
& Adjectives & E.194 & $12 \%$ \\
& & A.231 & $12.81 \%$ \\
& Conjunctions & E. 216 & $16.5 \%$ \\
& A.240 & $13.47 \%$ \\
& Auxiliaries & E.115 & $8.8 \%$ \\
& & A. 24 & $1.34 \%$ \\
\hline
\end{tabular}

b) Decontextualism is a thumbnail in this genre, both groups manipulate many linguistic tools to express context-free prospects, yet English transcends Arabic in this part. English records high rate in phrases and non-finite verbs occurrences. It records low rates in adverbs occurrence which distinguishes it from English, even though both languages use simple adverbs which only predict child spatial awareness.

Table 8

Decontextualism in English and Arabic data

\begin{tabular}{cccc}
\hline Trait & Linguistic Tool & Time of Occurrences & Percentages \\
\hline Decontextualism & Phrases & E.197 & $41 \%$ \\
& & A.93 & $13.96 \%$ \\
& Non-Finite Verbs & E.81 & $16.5 \%$ \\
& & A. 64 & $12.97 \%$ \\
& Adverbs & E.140 & $9.2 \%$ \\
& & A.81 & $4.49 \%$ \\
\hline
\end{tabular}

c) Belonging and othering, although these two traits are contradictive, magnificently in children genre, they worked together. Both languages depict both prospects, yet Arabic shows more belonging attitude than English does. Friendly othering trait is previewed differently, both groups prevail othering in special linguistic devices; English utilizes more pronouns and indefinite article, whereas Arabic employs more predictive adjectives and passive voice.

Table 9

Belonging and othering in English and Arabic data

\begin{tabular}{clcc}
\hline Trait & \multicolumn{1}{c}{ Linguistic Tool } & Time of Occurrences & Percentages \\
\hline \multirow{6}{*}{ Belonging } & Pronoun (I, my, we, our, & E.200 & $59.17 \%$ \\
& myself, you, your, etc) & A.331 & $73.23 \%$ \\
& Definite Articles & E. 183 & $69.3 \%$ \\
& & A.473 & $71.9 \%$ \\
& Attributive Adjectives & E. 126 & $65 \%$ \\
& Pronouns (They, he, she, & A.141 & $61 \%$ \\
& it etc.) & E. 138 & $40.8 \%$ \\
Friendly & Indefinite Article & A.121 & $26.76 \%$ \\
Othering & & E.81 & $30.68 \%$ \\
& Predictive Adjectives & A.184 & $28.1 \%$ \\
& & E. 68 & $35 \%$ \\
& Passive Voice & A.90 & $39 \%$ \\
& & E.4 & $1 \%$ \\
\hline
\end{tabular}

d) Imaginary and fun mode, both languages functionalize the same linguistic devices to present a fun and imaginary prospects. English exceeds Arabic in personification use, while Arabic transcends English in metaphor, exclamatory sentences and abstract nouns which make Arabic junior songs more imaginative and humorous than English does.

Lutfi Hussein, A., \& Ali Dawood, Z. (2018). Salient socio-stylistic traits of English and Arabic junior songs. International Journal of Linguistics, Literature and Culture, 4(4), 86-102. https://doi.org/10.21744/ijllc.v4n4.270 
Table 10

The imaginary and fun mode in English and Arabic data

\begin{tabular}{llcc}
\hline \multicolumn{1}{c}{ Trait } & Linguistic Tool & Time of Occurrences & Percentages \\
\hline & Personification & E.96 & $80.67 \%$ \\
& & A.117 & $54.16 \%$ \\
Imaginary & Metaphor & E. 15 & $12.6 \%$ \\
and & & A.80 & $37.03 \%$ \\
Fun Mode & \multirow{2}{*}{ Exclamatory Sentences } & E.6 & $2 \%$ \\
& & A.15 & $2.56 \%$ \\
& Abstract Nouns & E.214 & $27 \%$ \\
& & A.514 & $50.19 \%$ \\
\hline
\end{tabular}

e) Educational and deduction effects are vital in children genre since each linguistic text should have a purpose and the educational purpose is an ultimate one. The English language exceeds Arabic in this part, English uses more imperative sentences, modal, while Arabic uses more particles (not, oh), and slightly exceeds English in simile use

Table 11

Educational and deduction effects in English and Arabic data

\begin{tabular}{|c|c|c|c|}
\hline Trait & Linguistic Tool & Time of Occurrences & Percentages \\
\hline \multirow{8}{*}{$\begin{array}{l}\text { Educational and } \\
\text { Deduction Effects }\end{array}$} & Imperative Sentences & E.64 & $20 \%$ \\
\hline & \multirow{3}{*}{ Modals } & A. 75 & 12.82 \\
\hline & & E.38 & $2.9 \%$ \\
\hline & & A. 16 & $0.89 \%$ \\
\hline & Particle (not, oh-يا) & E.32 & $2.4 \%$ \\
\hline & \multirow{3}{*}{ Simile } & A.95 & $5.3 \%$ \\
\hline & & E. 8 & $6.7 \%$ \\
\hline & & A. 19 & $8.79 \%$ \\
\hline
\end{tabular}

f) Movement and Dynamism Effects, English is characterized by this trait and exceeds Arabic in this prospect with the overuse of dynamic verbs, against less use of stative verbs. Arabic only transcends English with frequency adverbs which are mainly few in occurrences. So, this prospect is in favor of the English part.

Table 12

Movement and dynamism effects in English and Arabic data

\begin{tabular}{cccc}
\hline Trait & Linguistic Tool & Time of Occurrences & Percentages \\
\hline Movement and & Dynamic Verbs & E.382 & $81.2 \%$ \\
Dynamism Effects & & A.342 & $73.3 \%$ \\
& Stative Verbs & E.88 & $18.7 \%$ \\
& & A. 124 & $26.6 \%$ \\
& Frequency Adverb & E.10 & $10 \%$ \\
& & A. 11 & $14 \%$ \\
\hline
\end{tabular}

g) Enquiring and Curiosity Mode, both languages use these prospects effectively. English functionalizes more interrogative sentences, adverbs of manner and degree. Arabic uses more metaphors and abstract nouns which present both groups parallel in this part but with different devices. 
Table 13

Enquiring and curiosity mode in English and Arabic data

\begin{tabular}{cccc}
\hline Trait & Linguistic Tool & Time of Occurrences & Percentages \\
\hline & Interrogative & E.27 & $9 \%$ \\
& & A.13 & $2.22 \%$ \\
Enquiring & Metaphor & E.15 & $12.6 \%$ \\
and & Abstract Nouns & A.80 & $37.03 \%$ \\
Curiosity & & E.214 & $27 \%$ \\
Mode & Manner Adverbs & A.514 & $50.19 \%$ \\
& & E. 44 & $31.4 \%$ \\
& & A.17 & $21 \%$ \\
& Degree Adverbs & E.9 & $6.5 \%$ \\
& & A.3 & $3.7 \%$ \\
\hline
\end{tabular}

\section{Conclusion}

The result and discussion of the socio-stylistic analysis of junior songs in both English and Arabic languages have led to the following findings:

a) Based on the lexical, syntactic, and figurative devices amalgamated with children register, stylistics provides the new consumers with the power to be motivated, provoked, and integrated socially.

b) Junior songs recall othering technique to integrate juniors socially and introduce little consumers to the other part of the world, grownup world or friendly othering. Language in these songs can be activated as a transformative power in society.

c) English junior songs are more descriptive by the overuse of adjectives, conjunctions, complex and compound sentences. On the other hand, Arabic is simpler and clear by the overuse of simple Declarative sentences.

d) Both groups present a semi-free context genre, but English is more decontextual than Arabic.

e) Belonging effects in Arabic prevail more than in English, but both languages conduct othering equally because othering enhances the socio prospects of this genre as an invitation to juniors in both cultures to be grafted socially, othering is not always a harmful sign, or against us.

f) Arabic junior songs are more imaginary and delightful than English. English children songs exceed Arabic in educational, instruction mode, and in movement and dynamism effects. Both languages witness parallel rates in enquiring and curiosity mode but with different devices.

\section{Recommendations}

a) Syllabus designers can achieve numerous prospects inside children songs taking into consideration the findings reached in this paper for each language and grafted these texts with many scientific, mathematical, and historical information dedicated to those individuals.

b) Text-book designers and translators can manipulate these results in transferring once cultural notion into another, using the most preferable linguistic prospects in each language, and introducing the new language learners to the sociological prospect of the new culture.

c) Syllabus designers can functionalize the resulted findings to manipulate particulars dedicated songs for special needs kids, who suffer from a disorder with social interaction (Autism) to encourage them and integrate socially.

d) Teachers and syllabus designers of primary schools can adopt the finding to cultivate the fresh children effortlessly with talking animals or fantasy creatures.

Notes

It is worthily mentioned that nonfinite verbs are called "Masdar/لمصدر"in Arabic which is either an exaggerated form of adjective derivative from a verb such as (فعال منثور فنتون , or abase verb preceded by' Result, Purpose, Exception, Preference' with specific particles such as (حتى, كي , مثل , كما , الا, سوى, (Drozdík, 2009:1). Further,

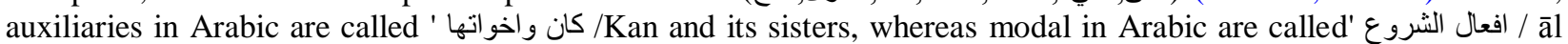
shirūu3 verbs' (intention verbs) (Tahir, 2009:6).

\footnotetext{
Lutfi Hussein, A., \& Ali Dawood, Z. (2018). Salient socio-stylistic traits of English and Arabic junior songs. International Journal of Linguistics, Literature and Culture, 4(4), 86-102. https://doi.org/10.21744/ijllc.v4n4.270
} 
Finally, the indefinite article, mainly in Arabic can be cited semantically, but some scholars propose that double articulation "'التنوين at the end of a word without "الصرة), 2007:61)

Conflict of interest statement and funding sources

The author declared that she has no competing interest. The study was financed by personal funding.

Statement of authorship

The author has a responsibility for the conception and design of the study. The author has approved the final article.

Acknowledgments

The author would like to thank the editor of IJLLC for their support, advice, and valuable time. 


\section{References}

Azhari, A. S. (2018). Speech Acts of Classroom Interaction. International Journal of Linguistics, Literature and Culture (IJLLC), 4(2), 24-45.

Briscoe, F., Arriaza, G., \& Henze, R. C. (2009). The power of talk: How words change our lives. Corwin Press.

Drozdik, L. (2009). The structure of non-finite relative clauses in arabic. Asian and African Studies, 18(2), $210-231$.

Ferguson, C. A. (1996). Sociolinguistic perspectives: papers on language in society, 1959-1994. Oxford University Press.

Fornäs, J. (2003). The words of music. Popular Music \& Society, 26(1), 37-51.

Hunt, P. (2004). International companion encyclopedia of children's literature. Routledge.

Koutchadé, I. S. (2017). An exploratory study of cohesive features in selected excerpts from Sefi Atta's news from home. International Journal of Linguistics, Literature and Culture (IJLLC), 3(6), 22-32.

Leech, G. (2014). Language in literature: Style and foregrounding. Routledge.

Mey, J. L., \& Brown, K. (2009). Concise Encyclopedia of Pragmatics. Elsevier Science.

Radford, A. (2004). English syntax: An introduction. Cambridge University Press.

Russell, D. L., \& Schneiderheinze, A. (2005). Understanding innovation in education using activity theory. Educational Technology \& Society, 8(1), 38-53.

Sibomana, E. (2018). Unpeeling the language policy and planning onion in Rwanda. International Journal of Social Sciences and Humanities (IJSSH), 2(2), 99-114.

Silberg, J., \& Schiller, P. B. (2002). The complete book of rhymes, songs, poems, fingerplays, and chants. Gryphon House, Inc..

Tahir, I. (2009). Copula in standard English and its Counterpart in Standard Arabic. Al-Fatih Journal, 39, 1-9.

Thornborrow, J., \& Wareing, S. (1998). Patterns in language: An introduction to language and literary style. Psychology Press.

Verdonk, P., \& Widdowson, H. G. (2002). Stylistics. Oxford University Press.

Wales, K. (2014). A dictionary of stylistics. Routledge.

الصر ايرة,نوح عطا الله(2007). التعريف و التنكير بين النحويين والبلاغيين, دراسة دلالية وظيفية(نماذج من السور المكية). رسالة ماجستير في اللغة

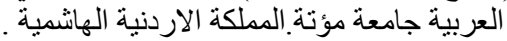

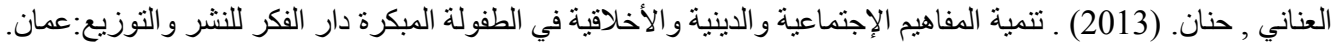

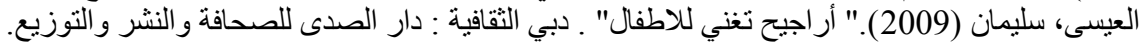

الهيتي , هادي نعمان (1986) ادب الاطفال فلسفته , فنونه, وسائطه الهيئة المصرية العامة للكتاب ـ القاهرة بالاشتر الك مع دار الثؤون الثقافية ـ بغداد

عبد الفتاح, اسماعيل (2000) ـ ادب الاطفال . مكتبة الدار العربية للكتاب : القاهرة

Lutfi Hussein, A., \& Ali Dawood, Z. (2018). Salient socio-stylistic traits of English and Arabic junior songs. International Journal of Linguistics, Literature and Culture, 4(4), 86-102. https://doi.org/10.21744/ijllc.v4n4.270 


\section{Biography of Authors}

Abbas Lutfi Hussein, an assistant professor (Ph.D.) of applied linguistics at
Mustansiriyah University, College of Arts, Baghdad, Iraq, teaching undergraduate and
graduate-level English language. His research interests include academic writing,
discourse, and applied linguistics.

